Elke Goos, Christina Sickfeld, Fabian Mauß, Lars Seidel, Branko Ruscic, Alexander Burcat, Thomas Zeuch,

Prompt NO formation in flames: The influence of NCN thermochemistry, Proceedings of the Combustion Institute, Volume 34 (2013) 657-666.

The original publication is available at www.elsevier.com

http://dx.doi.org/10.1016/j.proci.2012.06.128 


\title{
Prompt NO formation in flames: The influence of NCN thermochemistry
}

\author{
Elke Goos $^{1 *}$, Christina Sickfeld ${ }^{2}$, Fabian Mauß $^{3}$, Lars Seidel ${ }^{3}$, \\ Branko Ruscic ${ }^{4}$, Alexander Burcat ${ }^{5}$, Thomas Zeuch ${ }^{2 *}$ \\ ${ }^{1}$ Institute of Combustion Technology, DLR German Aerospace Center, Pfaffenwaldring 38-40, 70569 Stuttgart, Germany \\ ${ }^{2}$ Institut für Physikalische Chemie, Georg-August-Universität, Tammannstr. 6, 37077 Göttingen, Germany \\ ${ }^{3}$ Thermodynamics and Thermal Process Engineering, Brandenburg Technical University, 03046 Cottbus, Germany \\ ${ }^{4}$ Chemical Sciences and Engineering Division, Argonne National Laboratory, Argonne, IL 60439, USA. \\ ${ }^{5}$ Faculty of Aerospace Engineering, Technion IIT, Haifa 32000, Israel
}

\section{Corresponding authors:}

Email address: Elke.Goos@dlr.de (E.Goos) and tzeuch1@gwdg.de (T. Zeuch)

\section{Keywords:}

NCN heat of formation; NCN thermochemistry; Prompt NO formation; Methane flames, Acetylene flame

\begin{abstract}
The influence of the route via the NCN radical on NO formation in flames was examined from a thermochemistry and reaction kinetics perspective. A detailed analysis of available experimental and theoretical thermochemical data combined with an Active Thermochemical Tables analysis suggests a heat of formation of $457.8 \pm 2.0 \mathrm{~kJ} / \mathrm{mol}$ for NCN, consistent with carefully executed theoretical work of Harding et al. (2008) [5]. This value is significantly different from other previously reported experimental and theoretical values.

A combination of an extensively validated comprehensive hydrocarbon oxidation model extended by the GDFkin3.0_NCN-NO $\mathrm{N}_{\mathrm{x}}$ sub-mechanism reproduced NCN and NO mole fraction profiles in a recently characterized fuel-rich methane flame only when heat of formation values in the range of $445-453 \mathrm{~kJ} / \mathrm{mol}$ are applied. Sensitivity analysis revealed that the sensitivities of contributing steps to NO and NCN formation are strongly dependent on the absolute value of the heat of formation of NCN being used. In all flames under study the applied NCN thermochemistry highly influences simulated NO and NCN mole fractions.

The results of this work illustrate the thermochemistry constraints in the context of NCN chemistry which have to be taken into account for improving model predictions of NO concentrations in flames.
\end{abstract}




\section{Introduction}

Prompt NO formation is a fascinating topic in combustion chemistry since the first report of the phenomenon by Fenimore [1] more than thirty years ago. The issue remained controversial until now. Fenimore attributed the residual NO observed close to burner surface in hydrocarbon flames to reactions involving molecular nitrogen and free radicals of hydrocarbons. He suggested the reactions

$$
\mathrm{CH}+\mathrm{N}_{2} \rightarrow \mathrm{HCN}+\mathrm{N}
$$

and

$$
\mathrm{C}_{2}+\mathrm{N}_{2} \rightarrow \mathrm{CN}+\mathrm{CN}
$$

as potential sources of $\mathrm{NO}$ formation.

Later an examination of prompt NO formation by Miller and Bowman [2] concluded that reaction (R1a) is responsible for the phenomenon.

However, studies of Cui et al. [3] and Moskaleva and Lin [4] changed the picture by showing that (a) the spin-orbit coupling in reaction R1a was not strong enough to account for experimental observations regarding prompt NO formation and that (b) the alternative product channel

$$
\mathrm{CH}+\mathrm{N}_{2} \rightarrow \mathrm{NCN}+\mathrm{H}
$$

may better account for the experimental results reported at that time. These findings sparked many consecutive studies providing evidence for the suggested new route. A central issue emerged - from experimental, theoretical and modeling perspectives - namely the value of the rate coefficient of R1b in the practically important temperature range around $1500 \mathrm{~K}$. The extensive theoretical study on R1b by Harding et al. [5] agreed quantitatively with the shock tube study of Hanson and co-workers [6]. This finding clearly suggested that a central aspect of NCN reaction kinetics is settled. However, in their paper Harding et al. [5] pointed out that more accurate measurements of the heat of formation of NCN would significantly reduce the remaining uncertainty of their theoretical predictions below $2000 \mathrm{~K}$. Considering the endothermicity of R1b it is obvious that the heat of formation for NCN is likewise a highly sensitive quantity for modeling predictions, when the NCN pathway for prompt NO formation 
is implemented in reaction mechanisms. However, the relevance and extent of this uncertainty has not been systematically addressed $[7,8,9]$. So far reported values for the heat of formation of NCN differ by $\sim 20 \mathrm{~kJ} / \mathrm{mol}$ $[10,11,12]$.

El Bakali et al. [7] suggested, based on NCN measurements in flames, using a rate coefficient significantly faster than Moskaleva und Lin's value [4] but different from Harding et al. [5] and Vasudevan et al. [6]. In the more recent study of Lamoureux et al. [13] on CH, NCN and NO formation in fuel-rich methane and acetylene flames, the kinetic data of Hanson and co-workers for reaction (R1b) was used for kinetic modeling. The agreement of model predictions and experiment in this recent work also suggest a consistent picture regarding the modeling of prompt NO formation in methane flames.

However, all previous modeling studies on NO and NCN formation relied on kinetic models tested mainly for methane flames and much less for other fuels and other reactor types $[7,8,9]$. As a consequence the examination of a different fuel, e.g. acetylene in addition to methane, can imply using a different kinetic scheme [13] which is an unsatisfactory situation. Therefore it is highly desirable that up to date $\mathrm{NO}_{\mathrm{x}}$ sub-mechanisms including $\mathrm{NCN}$ chemistry are implemented into general hydrocarbon oxidation models, which map the complete set of combustion features (ignition delay times, flame speeds, speciation in reactors and flames, engine modeling) and fuels (C1-C4 hydrocarbons, $n$-heptane, toluene, etc.).

This point leads to the main objectives of the present work. First, the quality of available thermochemical data of NCN will be critically analyzed accompanied by quantum chemical calculations using state of the art techniques. Second, a general hydrocarbon oxidation mechanism will be extended for simulating NO formation via the NCN pathway. Based on the analysis of NCN thermochemistry and using a comprehensive kinetic model the effect of different scenarios for the absolute value of the heat of formation of NCN in model predictions regarding NO formation in hydrocarbon flames will be tested and implications for modeling NO and NCN formation will be discussed. 


\section{Methods}

\section{(a) Thermochemistry}

In order to use a consistent set of thermochemical data for kinetic modeling, enthalpies of formation obtained with the Active Thermochemical Tables (ATcT) $[14,15]$ approach were employed whenever possible and used to update the Goos, Burcat and Ruscic thermochemical database [16]. The ATcT enthalpies of formation utilized the most current version [17] of the underlying Thermochemical Network (TN), which was recently engaged to produce new thermochemistry data for phenyl and halobenzenes [18], bromine oxides [19] and small hydrocarbon radicals [20]. In addition, the enthalpy of formation of NCN (CAS-number: 2669-76-3) was examined in detail and re-evaluated using ATcT, and NCN heat capacity, entropy, and enthalpy increment; and the corresponding polynomials [21,22] were recalculated within the rigid-rotor-harmonic-oscillator (RRHO) approximation using the PAC program of McBride and Gordon [23], based on spectroscopic data listed in Jacox [24].

\section{(b) Kinetic model}

The hydrocarbon oxidation model is the current version of a C1-C4 fuel base-mechanism first reported in [25]. The compilation strategy aims at continuously increasing the number and type of targets for mechanism validation. Important extensions were the inclusion of $n$-heptane oxidation at high and low temperatures [26], a methanol oxidation sub-mechanism developed by Dryer group (see [27] and literature cited therein) and the oxidation of toluene as reported in [28]. In the most recent work the mechanism was augmented by adding branched C4-species [29].

The current model is validated in the temperature range of $500-2300 \mathrm{~K}$ for the full set of targets of first reports $[25,26]$ including flame speeds, ignition delay times, speciation in flames and reactors, soot precursor formation and HCCI engine ignition. The current range of fuels is methane, methanol, acetylene, ethylene, and ethane, propene and propane, $n$-butane and iso-butane, $n$-heptane, iso-octane and toluene.

For $\mathrm{NO}_{\mathrm{x}}$ modeling different mechanisms available in the literature have been tested [8,9]. In the final hydrocarbon$\mathrm{NO}_{\mathrm{x}}$ mechanism the $\mathrm{NO}_{\mathrm{x}}$ sub-model of the GDFkin3.0_NCN mechanism of the supplement of Lamoureux and coworkers [13] was used for extending our hydrocarbon mechanism. This $\mathrm{NO}_{\mathrm{x}}-\mathrm{NCN}$ sub-model is validated for recent measurements of $\mathrm{CH}, \mathrm{NCN}$ and $\mathrm{NO}$ mole fraction profiles in methane flames and was previously used to extend other hydrocarbon oxidation models for $\mathrm{NO}_{\mathrm{x}}$ predictions [30]. For assessing the influence of the heat of formation of NCN the effect of using different absolute values in model predictions was tested. We note that using 
different thermodynamic databases for other nitrogen containing species [9,13] had only negligible effects on model predictions. Calculations were performed in a straightforward manner with the combined mechanism and the effect on predicting $\mathrm{CH}$, NCN and NO mole fractions in various flames was analyzed.

The combined hydrocarbon- $\mathrm{NO}_{\mathrm{x}}$ mechanism being used in the present study consists of 224 species. Nearly all reactions were written in a reversible way. Only some global irreversible reactions producing more than 2 products were written allowing only the forward reaction direction. If used thermochemistry data is applied for calculating the backward reaction rate coefficients and forward and backward reaction directions are counted separately as individual, irreversible reactions; then the mechanism would contain 2610 irreversible reactions. Kinetic, thermodynamic and transport data are available on request (contact: elke.goos@dlr.de or tzeuch1@gwdg.de).).The recommended thermodynamic data of NCN is provided as Supplementary data. All calculations were performed with the current version of the DARS software package [31]. 


\section{Results and discussion}

In the introduction it was hinted that thermochemistry of NCN requires a more detailed scrutiny. Available heats of formation of NCN are rather inconsistent (see Table 1). Therefore implemented NCN routes in kinetic models for predicting $\mathrm{NO}_{\mathrm{x}}$ formation in flames may significantly depend on the value used in the thermochemical data set. The first part of this section will address this issue by re-examining the heat of formation of NCN within the context of Active Thermochemical Tables as well as previous experimental and theoretical work. Then the effects of NCN thermochemistry on prompt NO formation will be probed via flame simulations that use competing values for the enthalpy of formation of NCN. Finally, implications for modeling NO formation in flames will be discussed.

\subsection{Thermochemistry of NCN}

Taken per se, the temperature-dependent enthalpy increment, heat capacity, and entropy of NCN can be calculated reasonably well, because the influence of uncertainties in molecular properties of NCN is small in comparison to inconsistencies in the values for the heat of formation of NCN at standard conditions $\Delta_{\mathrm{f}} \mathrm{H}^{\circ}(\mathrm{NCN})$. Gurvich et al. [32] and JANAF Tables [33] provide $\Delta_{\mathrm{f}} \mathrm{H}^{\circ}{ }_{298 \mathrm{~K}}(\mathrm{NCN})=501 \pm 25 \mathrm{~kJ} / \mathrm{mol}$ and $473 \pm 21 \mathrm{~kJ} / \mathrm{mol}$, respectively, although they are based on the same approximate determination [34]. NIST WebBook [35] reports only the JANAF value and ignores Gurvich et al. and two newer results: the lower semi-experimental value $\Delta_{\mathrm{f}} \mathrm{H}^{\circ}{ }_{298 \mathrm{~K}}(\mathrm{NCN})=451.8 \pm 16.7 \mathrm{~kJ} / \mathrm{mol}$ of Clifford et al. [10] (from experimental electron affinity of NCN and theoretical gas-phase acidity of HNCN), and the more accurate but higher value of Bise et al. [11], who reported $\Delta_{\mathrm{f}} \mathrm{H}^{\circ}{ }_{0 \mathrm{~K}}(\mathrm{NCN})=466.0 \pm 2.9 \mathrm{~kJ} / \mathrm{mol}$, equivalent to $\Delta_{\mathrm{f}} \mathrm{H}^{\circ}{ }_{298 \mathrm{~K}}(\mathrm{NCN})=466.5 \pm 2.9 \mathrm{~kJ} / \mathrm{mol}$ (from the $\mathrm{N}-\mathrm{CN}$ bond dissociation energy and the $\mathrm{N}_{2}$ elimination energy from $\mathrm{NCN}$ ). Ignoring the older values from Gurvich and JANAF, the two newer choices for an experimentally based $\Delta_{\mathrm{f}} \mathrm{H}^{\circ}{ }_{298}(\mathrm{NCN})$ are nearly exclusive in the sense that their uncertainties do not provide a convincing overlap between the alternatives.

Very recently Canneaux et al. [12] examined NCN by several theoretical methods (CBS-QB3, CBS-APNO, G3//B3LYP, G3, and G4), and obtained $\Delta_{\mathrm{f}} \mathrm{H}^{\circ}{ }_{298}(\mathrm{NCN})=448.7 \pm 3.4 \mathrm{~kJ} / \mathrm{mol}$ as a weighted average, which favors the lower value of Clifford et al. [10] and directly negates the value of Bise et al. [11]. Pertinently, Clifford et al. [10] have accompanied their experimental effort with CBS-APNO calculations, which produced $\Delta_{\mathrm{f}} \mathrm{H}^{\circ}{ }_{298 \mathrm{~K}}(\mathrm{NCN})=$ $453 \mathrm{~kJ} / \mathrm{mol}$, in line with their semi-experimental value. Similarly, our own calculations at the G3, G3//B3LYP, CBS-Q, CBS-QB3, and CBS-APNO levels of theory suggest enthalpies of formation in the 443-452 kJ/mol range, in apparent support of the lower value of Clifford et al. [10]. However, earlier on, Martin et al. [36] have conducted 
CASSCF and CCSD(T) computations and selected a ZPE-uncorrected atomization energy of $1208 \pm 8 \mathrm{~kJ} / \mathrm{mol}$, which implies $\Delta_{\mathrm{f}} \mathrm{H}^{\circ}{ }_{298 \mathrm{~K}}(\mathrm{NCN})=465 \pm 8 \mathrm{~kJ} / \mathrm{mol}$, supporting (and predating) the higher value of Bise et al.[11].

In such situations, ATcT is usually capable of successfully arbitrating between inconsistent values by exploiting redundant thermochemical cycles in the Thermochemical Network (TN), providing that the body of thermochemically-relevant data is sufficiently rich. The TN includes the experimental determinations discussed above: electron affinity measurements of Clifford et al. [10] and Taylor et al. [37] as well as Bise et al.'s [11] determinations of the $\mathrm{N}-\mathrm{CN}$ bond dissociation energy and $\mathrm{N}_{2}$ elimination energy to triplet and singlet carbon. These are complemented by the available theoretical determinations: total atomization energy of Martin et al. [36] together with their isomerization energies to CNN and cyclic NCN at the ROHF-CCSD(T)/pVTZ level of theory, the CBS-APNO results of Clifford et al. [10], as well as our own G3, G3//B3LYP, CBS-Q, CBS-QB3, and CBSAPNO computations of total atomization energy of NCN, energy of $\mathrm{N}_{2}$ elimination to form triplet $\mathrm{C}$, and N-CN bond dissociation energy, and G3//B3LYP electron affinity, ionization energy, and energies of isomerization to CNN and cyclic NCN. Apparent abundance notwithstanding, the resulting number of thermochemical cycles involving NCN is meager when compared to most other chemical species in the TN, connecting relatively weakly to the rest of the TN. This makes the resulting ATcT value highly tentative, at best. Indeed, based on this TN, the ATcT approach suggests $\Delta_{\mathrm{f}} \mathrm{H}^{\circ}{ }_{298}(\mathrm{NCN})=445.73 \pm 1.70 \mathrm{~kJ} / \mathrm{mol}$, even lower than the value of Clifford et al. [10] and in apparent full agreement with Canneaux et al.'s value [12].

ATcT analysis of the provenance indicates that the value is dominated by single-reference computational results in the TN. The analysis also exposes some weaknesses of the experimental data: the determination [34] responsible for early values [32,33] is significantly less accurate than believed, the electron affinity measurements $[10,37]$ cannot influence the value of NCN without involving a theoretical gas-phase acidity, and the three thresholds of Bise et al. [11] appear to be less then fully mutually consistent irrespective of the assumed value for NCN. Thus, single-reference computations, which do appear mutually consistent when taken at face value, statistically prevail. However, an inspection of these computations reveals that single-reference descriptions of the ${ }^{3} \Sigma_{\mathrm{g}}^{-}$ground state of the NCN biradical suffer from spin contamination, although the effect on the computed energies is not immediately clear. The spin contamination problem has escaped the attention of Canneaux et al. [12] and Clifford et al. [10]. Unfortunately, the accuracy by which multireference methods reproduce energies generally lags behind that of single-reference methods, even when one juxtaposes state-of-the-art multireference methods with middle-of-the-pack single-reference methods. Indeed, though Martin et al.[36] explored a multireference 
approach, they chose to produce their final result with single-reference based CCSD(T)/pVTZ using restricted-open wavefunctions in order to limit spin contamination.

Clearly, in order to produce a reliable enthalpy of formation of NCN and resolve the controversy between low and high values, ATcT needs additional thermochemically-relevant information. Luckily, Harding et al. [5] have recently examined the potential energy surface of the $\mathrm{CH}+\mathrm{N}_{2}$ reaction using multireference methods (CASPT2 and internally contracted CAS $+1+2$ with and without Davidson correction), as well as restricted-open CCSD(T). Though the latter is similar to the approach of Martin et al. [36], Harding et al. [5] have used larger basis sets and extrapolated the results to the complete basis set limit. They found very good agreement between CAS+1+2+QC and $\operatorname{CCSD}(\mathrm{T})$ energies for all stationary points having a small $\mathrm{T}_{1}$ diagnostic $(<0.02)$. The agreement and smallness of the $\mathrm{T}_{1}$ diagnostic infuses additional confidence in their final RO-CCSD(T)/CBS//CASPT2/aug-cc-pVTZ ZPE-

corrected energies for $\quad{ }^{2} \mathrm{CH}+\mathrm{N}_{2} \rightarrow \mathrm{H}+\mathrm{NCN} \quad(81.8 \mathrm{~kJ} / \mathrm{mol}), \quad{ }^{4} \mathrm{CH}+\mathrm{N}_{2} \rightarrow \mathrm{H}+\mathrm{NCN} \quad(8.7 \mathrm{~kJ} / \mathrm{mol}), \quad$ and $\mathrm{H}+\mathrm{NCN} \rightarrow \mathrm{HCN}+\mathrm{N}(-17.37 \mathrm{~kJ} / \mathrm{mol})$. When analyzed by ATcT as a localized TN $[38,39]$ focused on NCN and aided with ATcT auxiliary thermochemistry for doublet and quartet $\mathrm{CH}$ (see also Ref. 40), N, H, and HCN; one finds that all three reaction energies are remarkably mutually consistent, showing that Harding et al. [5] also seem to correctly reproduce (within $\leq 1.7 \mathrm{~kJ} / \mathrm{mol}$ ) both the doublet-quartet splitting in $\mathrm{CH}$ and the reaction enthalpy of $\mathrm{CH}+\mathrm{N}_{2} \rightarrow \mathrm{HCN}+\mathrm{N}$ (both independent of $\left.\mathrm{NCN}\right)$. The ATcT result from this localized $\mathrm{TN}$ is $\Delta_{\mathrm{f}} \mathrm{H}^{\circ}{ }_{298}(\mathrm{NCN})$ $=457.8 \pm 2.0 \mathrm{~kJ} / \mathrm{mol}$, and represents the best currently available value. This enthalpy of formation is within the error bars of earlier theoretical result of Martin et al. [36] and refines it substantially, though it appears to no longer fully support the experimental result of Bise et al. [11].

The conclusion seems to be that single-reference based theoretical results produce enthalpies of formation of NCN that are decisively too low and tend to bias the ATcT analysis if taken at face value. The ATcT analysis reveals that available experimental determinations, which produce higher enthalpies of formation of NCN, are not as internally consistent as one would have initially hoped. Thus, the most credible value appears to emanate from the ATcT approach that relies on results from restricted-open coupled cluster methods, in lieu of as-yet-notdeveloped highly accurate multireference theoretical methods.

\subsection{Modeling of $\mathrm{CH}, \mathrm{NCN}$, and NO mol fraction profiles in flames}

In recent years many experimental and theoretical studies on the NCN and NO formation in flames have been reported [7,8,9,13,30, and literature cited therein]. The recent work of Lamoureux et al. [13] on NO and NCN 
formation in laminar premixed burner stabilized fuel rich methane and acetylene flames at 40 Torr is the central reference for the present study. Flame data including temperature profiles reported in this study are used in present work. In the same study an updated $\mathrm{NO}_{\mathrm{x}}$ mechanism is provided which, as explained above, is combined with our general hydrocarbon oxidation mechanism. We note that also Turanyi et al. [30] used the GDF_Kin mechanism in their uncertainty analysis of $\mathrm{NO}$ formation in flames.

Since the CH radical is a crucial precursor of NCN via reaction (R1b) an accurate simulation of this species is an important precondition for assessing NO formation via NCN in modeling studies. The upper panel of Fig. 1 shows the good agreement between the predicted and experimental $\mathrm{CH}$ mole fraction profiles, which is independent of the applied $\Delta_{\mathrm{f}} \mathrm{H}^{\circ}{ }_{298 \mathrm{~K}}(\mathrm{NCN})$ value. The slight overprediction by $15 \%$ is clearly within the experimental uncertainty. This is an important finding since $\mathrm{CH}$ mole fractions were, until now, not a target in the development of our multi-fuel model. It supports our compilation strategy aiming at comprehensive mechanisms whose application is not strictly limited to the targets of validation $[25,26,41]$

In the following, this mechanism will be used to elucidate the effect of NCN thermochemistry within the different NCN heat of formation scenarios (Case I: $\Delta_{\mathrm{f}} \mathrm{H}^{\circ}{ }_{298 \mathrm{~K}}(\mathrm{NCN})=445.7 \mathrm{~kJ} / \mathrm{mol}$ case II: $466.9 \mathrm{~kJ} / \mathrm{mol}$, case III: $457.8 \pm 2.0 \mathrm{~kJ} / \mathrm{mol}$, case IV: NCN thermodynamical data of GDF_KIN 3.0 mechanism, $\Delta_{\mathrm{f}} \mathrm{H}^{\circ}{ }_{298 \mathrm{~K}}(\mathrm{NCN})$ $=450 \mathrm{~kJ} / \mathrm{mol}$, slightly different heat capacities). The upper and lower panels of Fig. 1 show predicted NCN and NO concentrations for the different cases. The first observation is that predicted NCN and NO profiles differ significantly between the scenarios peaking for the GDF_KIN thermodynamical data (Case IV) and showing the lowest concentrations for Case II with the highest NCN heat of formation. Already at this stage it becomes clear that a serious problem for $\mathrm{NO}_{\mathrm{x}}$ modeling arises. When $\mathrm{NO}$ and NCN predictions differ to such an extent, the relative sensitivities of reactions on the pathways leading to NO formation will be affected. This is illustrated in Fig. 2, where the most sensitive reactions for $\mathrm{NO}$ formation within the $\mathrm{NO}_{\mathrm{x}}$ chemistry are shown for Cases I -IV. The surprising result is that not only the absolute sensitivities differ significantly (NCN-sensitivities) but also the ranking of sensitive reactions involving nitrogen chemistry has changed in case of sensitivities for NO. Reaction (R1b) is only for Case I the most sensitive reaction for NCN and NO formation and also the sensitivities for $\mathrm{NCN}+\mathrm{O}$ and $\mathrm{NCN}+\mathrm{H}$ are affected. The most sensitive reactions of the baseline hydrocarbon mechanism are also shown in Fig. 2, but their sensitivities remain largely unchanged. We note that for the sensitive $\mathrm{CH}_{3}+\mathrm{O}$ reaction the results of our extensive experimental study were used in the kinetic model [42]. 
At higher equivalence ratios the sensitivity of the thermochemistry of NCN on NO prediction is stronger due to increased CH concentrations which imply more $\mathrm{NO}$ formation via reaction $\mathrm{CH}+\mathrm{N}_{2}=\mathrm{NCN}+\mathrm{H}(\mathrm{R} 1 \mathrm{~b})$.

In principle the effect of temperature is also profound, as the backward reaction rate of reaction (R1b) is highly sensitive on the NCN thermochemistry.

The differences shown in Figs. 1 and 2 are almost as significant as the differences being observed by Turanyi and co-workers [30]: They compared reaction sensitivities for $\mathrm{NO}$ formation using different $\mathrm{NO}_{\mathrm{x}}$ mechanisms featuring either R1a or R1b as the route leading to prompt NO.

Interestingly, the very reasonable decision of Turanyi and co-workers [30] to use a consistent thermochemical dataset has led to a confusing situation. Their use of the GDF_KIN mechanism as a basis for their uncertainty analysis is motivated by the good performance of this model regarding the simulation of NO formation via NCN. But this is only true within the case I or case IV/GDF_KIN thermodynamical data scenario as we have illustrated in Fig. 1, but not for the Case III scenario which applies for the work of Turanyi and co-workers [30].

The implication is drastic: When the value of the NCN heat of formation recommended in the present study $\left(\Delta_{\mathrm{f}} \mathrm{H}^{\circ}{ }_{298 \mathrm{~K}}(\mathrm{NCN})=457.8 \mathrm{~kJ} / \mathrm{mol}\right.$, Case III) prevail, many conclusions of modeling studies on prompt NO formation via NCN become questionable and have to be reexamined.

A short literature survey for existing hydrocarbon oxidation mechanisms featuring $\mathrm{NO}_{\mathrm{x}}$ sub-models reveals that both high and low enthalpies of formation of NCN (Cases I and II) are commonly used (see Table 1). We further note that NCN and NO concentration are ca. 20\% lower when, instead of the Case IV/GDF_KIN scenario, our representation of heat capacities is used together with $\Delta_{\mathrm{f}} \mathrm{H}^{\circ}{ }_{298 \mathrm{~K}}(\mathrm{NCN})=450 \mathrm{~kJ} / \mathrm{mol}$.

In Fig. 3 the modeling results for the acetylene flames being examined by Lamoureux et al. [13] are shown. We see in the left panels that for the stoichiometric case a satisfactory agreement is found. However, the NO mole fraction is slightly underpredicted for Case I and IV and more severely for Cases II and III. The peak concentrations of CH and NCN are captured quite well while the positions are slightly shifted in our model prediction. For the fuel rich flame (right panels of Fig. 3) both the $\mathrm{CH}$ and NCN mole fractions are overpredicted for all cases. Taking into account that $\mathrm{CH}$ mole fractions in acetylene flames were not a target of our model, the agreement is still satisfactory. 
In the modeling part of Lamoureux et al.'s work [13] the Skevis and Lindstedt acetylene mechanism [43] was used being augmented by the $\mathrm{NO}_{\mathrm{x}}$ sub-mechanism of the GDF_Kin 3.0 model. This model showed the same tendency to overpredict $\mathrm{CH}$ in the fuel rich flame but captures better the $\mathrm{CH}$ and NCN peak positions (not shown here, see Fig. 11 in [13]). The most intriguing point, however, is the following: Lamoureux et al. found with this model a significant underprediction of NCN concentration for both flames. This finding was rationalized by proposing alternative routes to $\mathrm{NCN}$ formation like $\mathrm{C}_{2} \mathrm{O}+\mathrm{N}_{2} \rightarrow \mathrm{NCN}+\mathrm{CO}$. Adding the same $\mathrm{NO}_{\mathrm{x}}$ sub-mechanism to our general hydrocarbon oxidation model results in acceptable agreement for the predicted $\mathrm{CH}$, NCN and NO mole fraction profiles for the stoichiometric flame (when the heat of formation issue is ignored for a moment). The overprediction of NO and NCN in the Case I and IV scenarios for the fuel rich flame rather points to difficulties in modeling $\mathrm{CH}$ mole fraction profiles and does not indicate missing NCN chemistry. The different model predictions are most probably related to significant differences of the models in predicting the mole fractions of $\mathrm{H}$ and $\mathrm{O}$ atoms, which consume NCN.

These findings call for improving our capability of modeling $\mathrm{CH}$ as well as $\mathrm{H}$ and $\mathrm{O}$ atom mole fractions in acetylene flames, and focus our intention on the predictive power of single fuel and single reactor type models when the range of test cases is extended. The very broad target range of the general hydrocarbon oxidation mechanism limits systematic difficulties in predicting $\mathrm{H}$ and $\mathrm{O}$ atom concentrations.

However, for settling the issue of additional routes to NCN, the further examination of speciation in acetylene by comprehensive models seems necessary. 


\section{Conclusions}

In the present study the thermochemistry of NCN and its role for model predictions of NO formation in flames has been critically analyzed. The detailed inspection of the recent high level calculations of Harding et al. [5] of the hypersurface for reaction (R1b) combined with the Active Thermochemical Tables analysis indicates that a heat of formation $\Delta_{\mathrm{f}} \mathrm{H}^{\circ}{ }_{298 \mathrm{~K}}(\mathrm{NCN})=457.8 \pm 2.0 \mathrm{~kJ} / \mathrm{mol}$ for $\mathrm{NCN}$ leads to a consistent picture from a state of the art theoretical perspective. This value differs significantly, however, from other previously reported experimental [11] and theoretical values [12, 36].

The kinetic modeling part of this work illustrated that model predictions based on an established comprehensive multi-fuel hydrocarbon oxidation model $[25,26,29]$ being extended by the recently updated $\mathrm{NO}_{\mathrm{x}}$ sub-mechanism of the GDF-Kin model [13] can in principle reproduce $\mathrm{CH}, \mathrm{NCN}$ and NO profiles in a recently characterized fuel-rich methane flame [13]. However, the agreement of model predictions for NCN and NO mole fraction profiles in the present and several other previous literature studies for various flames is only given when the applied heat of formation of NCN in the thermochemical database is close to or below the value being reported by Clifford et al. [10] being around $450 \mathrm{~kJ} / \mathrm{mol}$. In case the more recently reported value of Bise et al. [11] (466.9 kJ/mol) or the recommended value of the present study $(457.8 \mathrm{~kJ} / \mathrm{mol})$ is used, the model predictions differ significantly from the experimental references. In addition the ranking and the absolute value of reaction sensitivities are significantly changed when the NCN heat of formation is altered.

We therefore have to conclude that current understanding of prompt NO formation might be based on model predictions which used in general rather improper representations of NCN thermochemistry.

In a future effort we therefore will look carefully on the reaction kinetics of prompt NO formation to develop a comprehensive kinetic model in agreement with thermochemistry constraints. 


\section{Acknowledgements:}

Funding by the Energy Program of the German Aerospace Center (DLR) is gratefully acknowledged by E.G. Funding by the Fonds der Chemischen Industrie is gratefully acknowledged by T.Z. The work at Argonne National Laboratory was performed under the auspices of the U.S. Department of Energy, Office of Basic Energy Sciences, Division of Chemical Sciences, Geosciences, and Biosciences, under Contract No. DE-AC02-06CH11357. E.G., F.M., L.S. and T.Z. acknowledge support from COST Action CM0901: "Detailed chemical kinetic models for cleaner combustion”.

\section{Appendix A: Supplementary data (Thermochemistry data of NCN)}

Supplementary data associated with this article can be found in the online version at http://dx.doi.org/10.1016/j.proci.2012.06.128

and in front of the references, near the end of this file 
Fig. 1:

Simulated and measured mole fraction profiles of $\mathrm{CH}$, NO (upper panel) and NCN (lower panel) in a fuel rich $\mathrm{CH}_{4}-\mathrm{O}_{2}-\mathrm{N}_{2}$ flame: $\Phi=1.25, \mathrm{x}\left(\mathrm{CH}_{4}\right)=0.124, \mathrm{x}\left(\mathrm{O}_{2}\right)=0.198, \mathrm{x}\left(\mathrm{N}_{2}\right)=0.678$; for experimental details see [13]. Cases I-IV: $\Delta_{\mathrm{f}} \mathrm{H}_{298}=445.7 \mathrm{~kJ} / \mathrm{mol}(\mathrm{I}), \Delta_{\mathrm{f}} \mathrm{H}_{298}=466.5 \mathrm{~kJ} / \mathrm{mol}(\mathrm{II}), \Delta_{\mathrm{f}} \mathrm{H}_{298}=457.8 \mathrm{~kJ} / \mathrm{mol}$ (III), $\Delta_{\mathrm{f}} \mathrm{H}_{298}=450.0 \mathrm{~kJ} / \mathrm{mol}(\mathrm{IV})$.

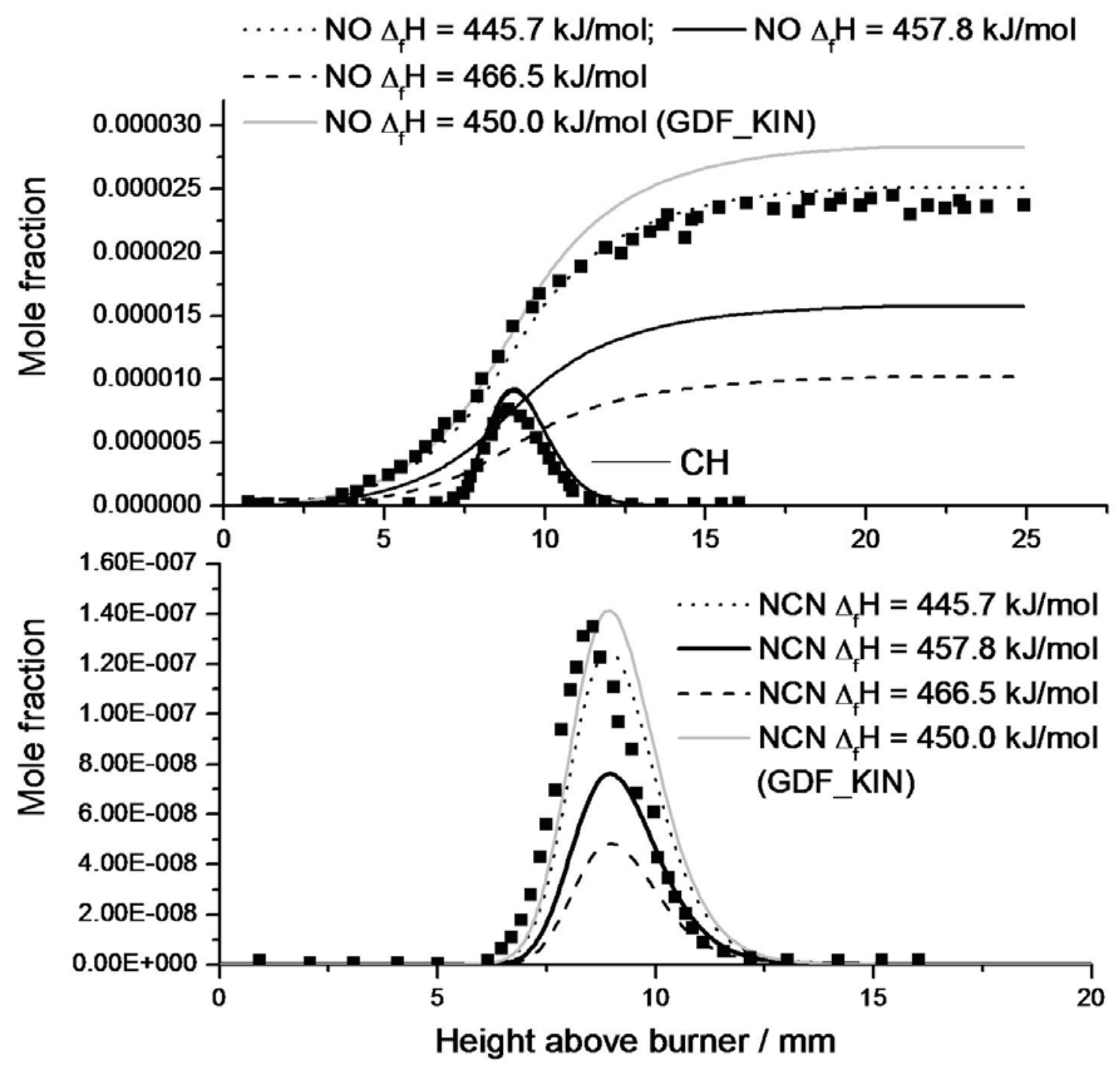


Fig. 2:

Relative reaction sensitivity coefficients for the mole fractions of NO (upper panel) and NCN (lower panel) of a fuel rich laminar methane $(\phi=1.25)$ [13] for different heat of formation of NCN.
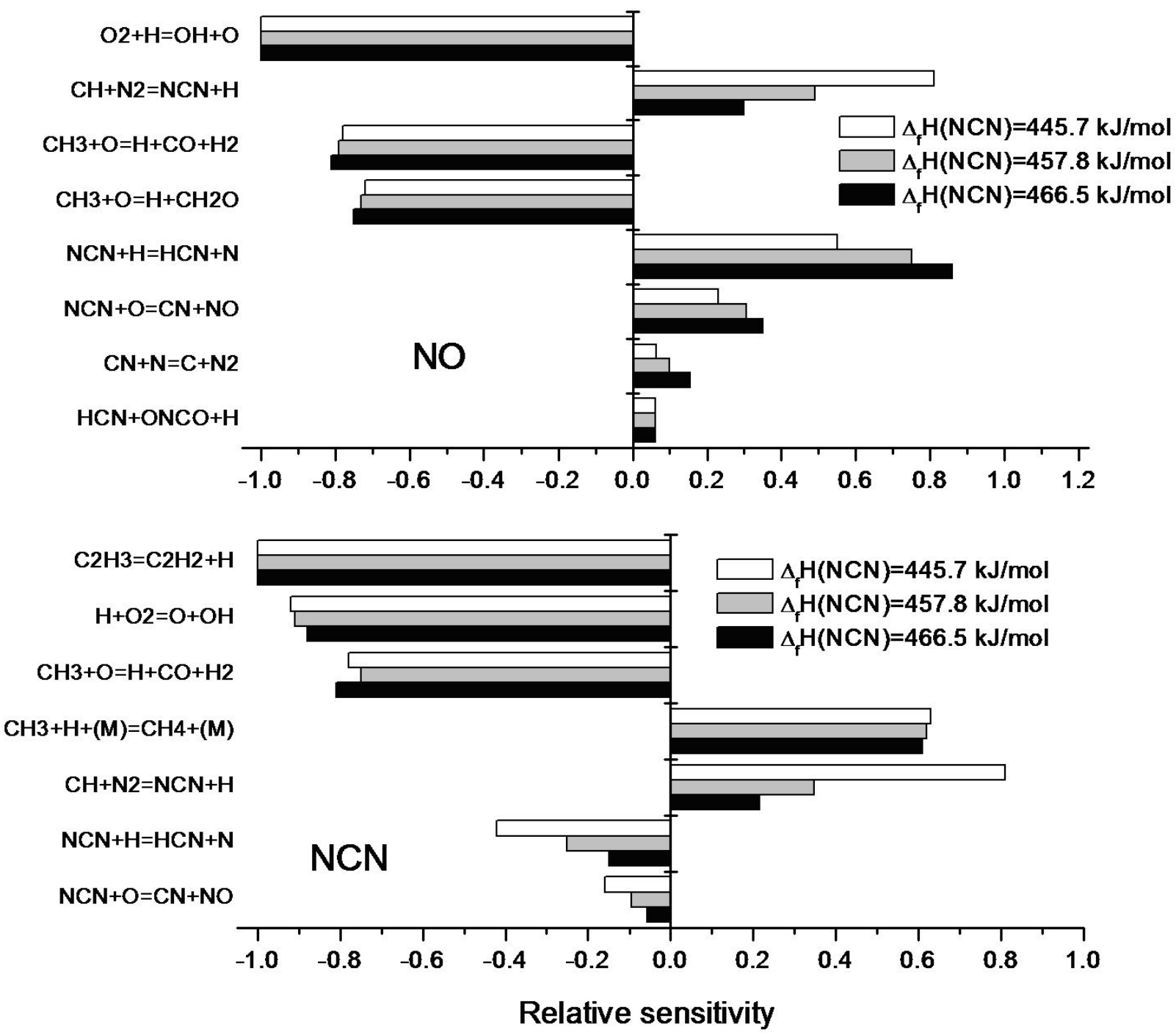
Fig. 3:

Simulated and measured mole fraction profiles of $\mathrm{CH}$, NO (upper panels) and NCN (lower panels) in acetylene-air flames ([13]). Stoichiometric flame: $\Phi=1.0, \mathrm{x}\left(\mathrm{C}_{2} \mathrm{H}_{2}\right)=0.067, \mathrm{x}\left(\mathrm{O}_{2}\right)=0.167, \mathrm{x}\left(\mathrm{N}_{2}\right)=0.766$. Fuel rich flame: $\Phi=1.25, \mathrm{x}\left(\mathrm{C}_{2} \mathrm{H}_{2}\right)=0.0826, \mathrm{x}\left(\mathrm{O}_{2}\right)=0.165, \mathrm{x}\left(\mathrm{N}_{2}\right)=0.753$; for experimental details see [13]. Cases I-IV: $\Delta_{\mathrm{f}} \mathrm{H}_{298}=445.7 \mathrm{~kJ} / \mathrm{mol}$ (I), $\Delta_{\mathrm{f}} \mathrm{H}_{298}=466.5 \mathrm{~kJ} / \mathrm{mol}$ (II), $\Delta_{\mathrm{f}} \mathrm{H}_{298}=457.8 \mathrm{~kJ} / \mathrm{mol}$ (III), $\Delta_{\mathrm{f}} \mathrm{H}_{298}=450.0 \mathrm{~kJ} / \mathrm{mol}(\mathrm{IV})$.
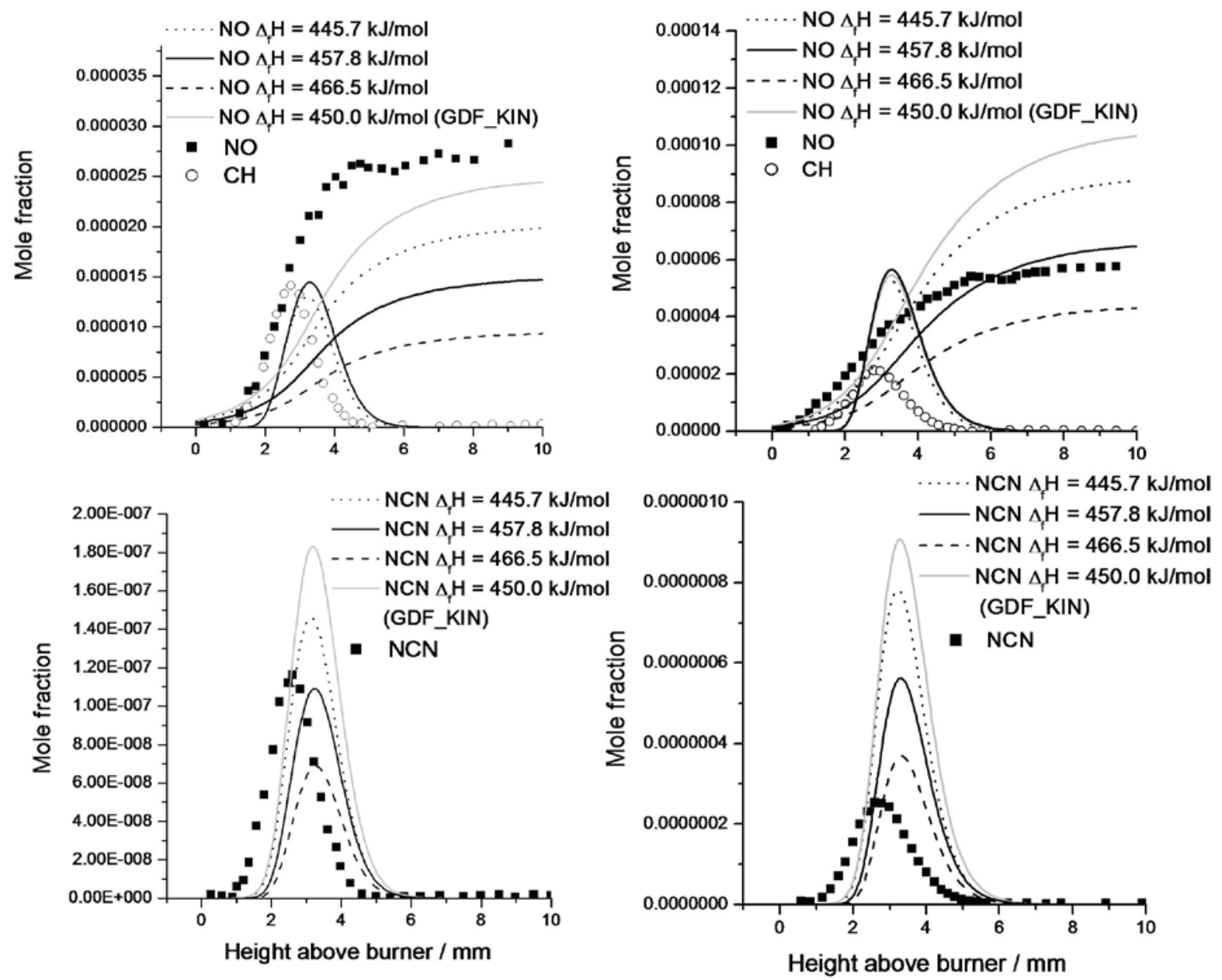
Table 1:

Experimental and calculated Standard Heat of Formation of NCN and its usage in some modeling studies

\begin{tabular}{|c|c|c|}
\hline $\begin{array}{l}\Delta_{\mathrm{f}} \mathrm{H}^{\circ}{ }_{298 \mathrm{~K}}(\mathrm{NCN}) \\
\mathrm{kJ} / \mathrm{mol}\end{array}$ & Experimental or calculated values & Used in prior modeling studies \\
\hline $501 \pm 25$ & Gurvich [32] & $\begin{array}{l}\text { NASA program CEA and Thermo } \\
\text { Build [44a] with NCN data from } \\
\text { [44b]. }\end{array}$ \\
\hline $473 \pm 21$ & JANAF [33], listed by NIST Webbook [35] & Zamansky and Lissianski [45] \\
\hline $465 \pm 8$ & $\begin{array}{l}\text { Martin et al. [36] multireference methods (recalculated } \\
\text { from atomization energy) }\end{array}$ & \\
\hline $466.5 \pm 2.9$ & $\begin{array}{l}\text { Bise et al. [11] (recalculated from } \Delta \mathrm{H}_{\mathrm{f}}^{\circ} 0 \mathrm{~K}=466.0 \pm 2.9 \\
\mathrm{~kJ} / \mathrm{mol} \text { ) }\end{array}$ & $\begin{array}{l}\text { Garner et al. [46], Konnov [9], } \\
\text { Vasudevan et al. [6], Zhu et al. } \\
\text { [47]. }\end{array}$ \\
\hline 464 & Moskaleva, Lin [4], Mebel et al.[48] & $\begin{array}{l}\text { Gersen et al. [49] modified GRI } \\
\text { mechanism }\end{array}$ \\
\hline Unknown value & & Sepman et al. [50] \\
\hline 459 & $\begin{array}{l}\text { Harding et al. [5] multireference methods (calculated } \\
\text { from reaction endothermicity of } \mathrm{CH}+\mathrm{N}_{2} \rightarrow \mathrm{NCN}+\mathrm{H} \text { ) }\end{array}$ & \\
\hline $457.8 \pm 2.0$ & This work, recommended value & \\
\hline $451.8 \pm 16.7$ & Clifford et al.[10] & $\begin{array}{l}\text { Benard et al.[51], El Bakali et } \\
\text { al.[7], Lamoureux et al. (107.7 } \\
\text { kcal/mol) [13], Xu and Lin [52], } \\
\text { Zhu et al. [53]. }\end{array}$ \\
\hline $450-450.2$ & Melius [54] & $\begin{array}{l}\text { Dagaut, Glarborg and Alzueta } \\
\text { [55a], Sarathy et al. [55b], all } \\
\text { LLNL mechanisms published } \\
\text { before December 2011: e.g. [56] }\end{array}$ \\
\hline $448.7 \pm 3.4$ & $\begin{array}{l}\text { Canneaux et al. [12], weighted average of single } \\
\text { reference methods }\end{array}$ & \\
\hline 444.5 & $\begin{array}{l}\text { Dammeier and Friedrichs [57] (calculated from } \Delta \mathrm{H}_{\mathrm{f}}{ }^{\circ}{ }_{0 \mathrm{~K}}= \\
444 \mathrm{~kJ} / \mathrm{mol} \text { ) }\end{array}$ & \\
\hline $443-452$ & This work, single reference methods & \\
\hline
\end{tabular}




\section{The References are at the end of the file}

\section{Supplementary data:}

\section{Thermochemical data of NCN with heat of formation at $298 \mathrm{~K}=457.8 \mathrm{~kJ} / \mathrm{mol}$ in 9-term-NASA-format:}

NCN HF298=457.8+/-2.๑ kJ REF=ATCT D 2012

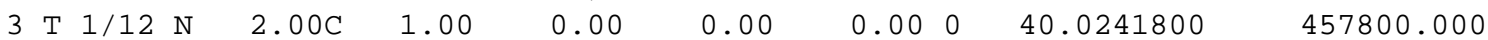

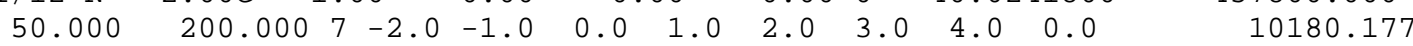

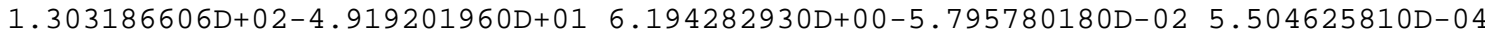

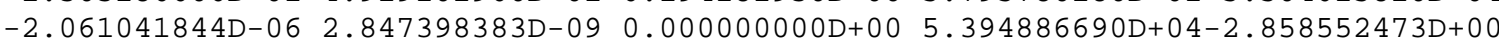

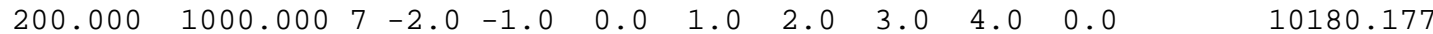

$-4.703840330 D+045.955107910 D+02-6.666804130 D-03 \quad 1.620476680 D-02-1.627518262 D-05$

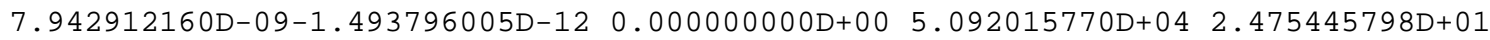

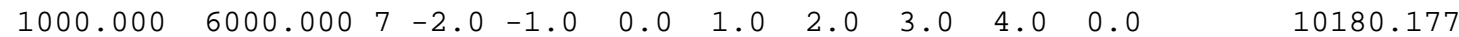

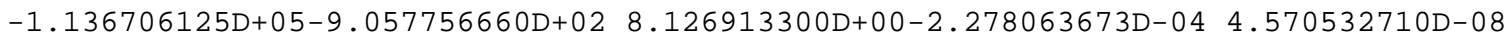

$-5.163206090 D-12 \quad 3.031473359 D-16 \quad 0.00000000 \odot D+0 \odot \quad 5.755465440 D+04-2.241696262 D+01$

Thermochemical data of NCN with heat of formation at $298 \mathrm{~K}=457.8 \mathrm{~kJ} / \mathrm{mol}$ in 7-term-NASA-format:

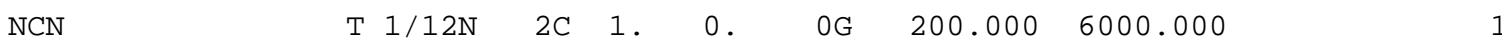

$5.68743460 \mathrm{E}+\odot \odot 1.82663439 \mathrm{E}-03-7.07551130 \mathrm{E}-07 \quad 1.19517763 \mathrm{E}-10-7.31862017 \mathrm{E}-15$

$5.30454071 \mathrm{E}+04-6.31950475 \mathrm{E}+0 \odot \quad 2.79807986 \mathrm{E}+0 \odot \quad 1.00008861 \mathrm{E}-02-9.59242059 \mathrm{E}-06$

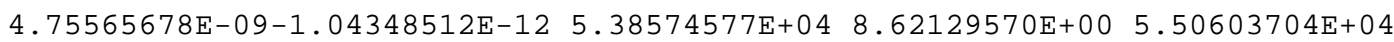

Thermochemical data of NCN with heat of formation at $298 \mathrm{~K}=457.8 \mathrm{~kJ} / \mathrm{mol}$ in table format:

\begin{tabular}{|c|c|c|c|c|c|}
\hline $\mathbf{T}$ & CP & $\mathrm{H}-\mathrm{H} 298$ & $\mathrm{~S}$ & $-(\mathrm{G}-\mathrm{H} 298) / \mathrm{T}$ & $\mathbf{H}$ \\
\hline $\mathbf{K}$ & $\mathrm{J} /(\mathrm{mol} \mathrm{K})$ & $\mathrm{kJ} / \mathrm{mol}$ & $\mathrm{J} /(\mathrm{mol} \mathrm{K})$ & $\mathrm{J} /(\mathrm{mol} \mathrm{K})$ & $\mathrm{kJ} / \mathrm{mol}$ \\
\hline 0 & & -10.180 & & & 447.620 \\
\hline 50 & 29.110 & -8.725 & 166.624 & 341.127 & 449.075 \\
\hline 60 & 29.152 & -8.434 & 171.935 & 312.499 & 449.366 \\
\hline 70 & 29.269 & -8.142 & 176.436 & 292.748 & 449.658 \\
\hline 80 & 29.498 & -7.848 & 180.358 & 278.459 & 449.952 \\
\hline 90 & 29.853 & -7.551 & 183.852 & 267.756 & 450.249 \\
\hline 100 & 30.328 & -7.251 & 187.021 & 259.527 & 450.549 \\
\hline 110 & 30.902 & -6.945 & 189.937 & 253.070 & 450.855 \\
\hline 120 & 31.549 & -6.632 & 192.653 & 247.923 & 451.168 \\
\hline 130 & 32.240 & -6.313 & 195.206 & 243.771 & 451.487 \\
\hline 140 & 32.952 & -5.987 & 197.621 & 240.389 & 451.813 \\
\hline 150 & 33.668 & -5.654 & 199.919 & 237.615 & 452.146 \\
\hline 160 & 34.374 & -5.314 & 202.114 & 235.328 & 452.486 \\
\hline 170 & 35.062 & -4.967 & 204.219 & 233.436 & 452.833 \\
\hline 180 & 35.726 & -4.613 & 206.242 & 231.870 & 453.187 \\
\hline 190 & 36.365 & -4.253 & 208.191 & 230.573 & 453.547 \\
\hline 200 & 36.977 & -3.886 & 210.072 & 229.501 & 453.914 \\
\hline 210 & 37.565 & -3.513 & 211.890 & 228.619 & 454.287 \\
\hline 220 & 38.129 & -3.135 & 213.651 & 227.899 & 454.665 \\
\hline 230 & 38.671 & -2.751 & 215.358 & 227.317 & 455.049 \\
\hline 240 & 39.194 & -2.361 & 217.015 & 226.853 & 455.439 \\
\hline 250 & 39.700 & -1.967 & 218.625 & 226.492 & 455.833 \\
\hline
\end{tabular}




\begin{tabular}{|c|c|c|c|c|c|}
\hline$T$ & $\mathrm{CP}$ & H-H298 & $\mathbf{S}$ & $-(\mathrm{G}-\mathrm{H} 298) / \mathrm{T}$ & $\mathbf{H}$ \\
\hline $\mathbf{K}$ & $\mathrm{J} /(\mathrm{mol} \mathrm{K})$ & $\mathrm{kJ} / \mathrm{mol}$ & $\mathrm{J} /(\mathrm{mol} \mathrm{K})$ & $\mathrm{J} /(\mathrm{mol} \mathrm{K})$ & $\mathrm{kJ} / \mathrm{mol}$ \\
\hline 260 & 40.190 & -1.567 & 220.192 & 226.220 & 456.233 \\
\hline 270 & 40.666 & -1.163 & 221.718 & 226.025 & 456.637 \\
\hline 280 & 41.131 & -0.754 & 223.205 & 225.898 & 457.046 \\
\hline 290 & 41.584 & -0.340 & 224.656 & 225.830 & 457.460 \\
\hline 298.15 & 41.946 & 0.000 & 225.814 & 225.814 & 457.800 \\
\hline 300 & 42.028 & 0.078 & 226.073 & 225.815 & 457.878 \\
\hline 320 & 42.888 & 0.927 & 228.813 & 225.917 & 458.727 \\
\hline 340 & 43.715 & 1.793 & 231.438 & 226.165 & 459.593 \\
\hline 360 & 44.514 & 2.675 & 233.960 & 226.529 & 460.475 \\
\hline 380 & 45.283 & 3.573 & 236.387 & 226.984 & 461.373 \\
\hline 400 & 46.024 & 4.486 & 238.729 & 227.513 & 462.286 \\
\hline 420 & 46.737 & 5.414 & 240.992 & 228.101 & 463.214 \\
\hline 440 & 47.421 & 6.356 & 243.182 & 228.737 & 464.156 \\
\hline 460 & 48.077 & 7.311 & 245.305 & 229.412 & 465.111 \\
\hline 480 & 48.705 & 8.279 & 247.364 & 230.117 & 466.079 \\
\hline 500 & 49.304 & 9.259 & 249.365 & 230.847 & 467.059 \\
\hline 520 & 49.875 & 10.251 & 251.310 & 231.597 & 468.051 \\
\hline 540 & 50.419 & 11.254 & 253.202 & 232.362 & 469.054 \\
\hline 560 & 50.936 & 12.267 & 255.045 & 233.140 & 470.067 \\
\hline 580 & 51.428 & 13.291 & 256.841 & 233.926 & 471.091 \\
\hline 600 & 51.895 & 14.324 & 258.593 & 234.719 & 472.124 \\
\hline 620 & 52.338 & 15.366 & 260.302 & 235.517 & 473.166 \\
\hline 640 & 52.759 & 16.417 & 261.970 & 236.318 & 474.217 \\
\hline 660 & 53.158 & 17.477 & 263.600 & 237.120 & 475.277 \\
\hline 680 & 53.536 & 18.544 & 265.192 & 237.922 & 476.344 \\
\hline 700 & 53.895 & 19.618 & 266.749 & 238.724 & 477.418 \\
\hline 720 & 54.235 & 20.699 & 268.272 & 239.523 & 478.499 \\
\hline 740 & 54.558 & 21.787 & 269.763 & 240.320 & 479.587 \\
\hline 760 & 54.864 & 22.882 & 271.222 & 241.115 & 480.682 \\
\hline 780 & 55.154 & 23.982 & 272.651 & 241.905 & 481.782 \\
\hline 800 & 55.430 & 25.088 & 274.051 & 242.691 & 482.888 \\
\hline 820 & 55.691 & 26.199 & 275.423 & 243.473 & 483.999 \\
\hline 840 & 55.940 & 27.315 & 276.768 & 244.250 & 485.115 \\
\hline 860 & 56.176 & 28.436 & 278.087 & 245.021 & 486.236 \\
\hline 880 & 56.400 & 29.562 & 279.381 & 245.787 & 487.362 \\
\hline 900 & 56.614 & 30.692 & 280.651 & 246.548 & 488.492 \\
\hline 920 & 56.817 & 31.827 & 281.897 & 247.303 & 489.627 \\
\hline 940 & 57.010 & 32.965 & 283.121 & 248.052 & 490.765 \\
\hline 960 & 57.194 & 34.107 & 284.323 & 248.795 & 491.907 \\
\hline 980 & 57.369 & 35.253 & 285.504 & 249.532 & 493.053 \\
\hline 1000 & 57.536 & 36.402 & 286.665 & 250.264 & 494.202 \\
\hline 1020 & 57.695 & 37.554 & 287.806 & 250.988 & 495.354 \\
\hline 1040 & 57.847 & 38.709 & 288.928 & 251.707 & 496.509 \\
\hline 1060 & 57.993 & 39.868 & 290.031 & 252.420 & 497.668 \\
\hline 1080 & 58.131 & 41.029 & 291.117 & 253.127 & 498.829 \\
\hline 1100 & 58.264 & 42.193 & 292.184 & 253.827 & 499.993 \\
\hline 1120 & 58.390 & 43.360 & 293.235 & 254.521 & 501.160 \\
\hline 1140 & 58.511 & 44.529 & 294.270 & 255.210 & 502.329 \\
\hline 1160 & 58.627 & 45.700 & 295.289 & 255.892 & 503.500 \\
\hline 1180 & 58.738 & 46.874 & 296.292 & 256.568 & 504.674 \\
\hline 1200 & 58.845 & 48.049 & 297.280 & 257.239 & 505.849 \\
\hline 1250 & 59.092 & 50.998 & 299.687 & 258.889 & 508.798 \\
\hline 1300 & 59.314 & 53.958 & 302.009 & 260.503 & 511.758 \\
\hline 1350 & 59.516 & 56.929 & 304.251 & 262.082 & 514.729 \\
\hline 1400 & 59.698 & 59.910 & 306.419 & 263.627 & 517.710 \\
\hline 1450 & 59.865 & 62.899 & 308.517 & 265.139 & 520.699 \\
\hline 1500 & 60.016 & 65.896 & 310.549 & 266.619 & 523.696 \\
\hline
\end{tabular}




\begin{tabular}{|c|c|c|c|c|c|}
\hline$T$ & $\mathrm{CP}$ & H-H298 & $\mathbf{S}$ & $-(\mathrm{G}-\mathrm{H} 298) / \mathrm{T}$ & $\mathbf{H}$ \\
\hline $\mathbf{K}$ & $\mathrm{J} /(\mathrm{mol} \mathrm{K})$ & $\mathrm{kJ} / \mathrm{mol}$ & $\mathrm{J} /(\mathrm{mol} \mathrm{K})$ & $\mathrm{J} /(\mathrm{mol} \mathrm{K})$ & $\mathrm{kJ} / \mathrm{mol}$ \\
\hline 1550 & 60.154 & 68.900 & 312.519 & 268.068 & 526.700 \\
\hline 1600 & 60.281 & 71.911 & 314.431 & 269.487 & 529.711 \\
\hline 1650 & 60.398 & 74.928 & 316.288 & 270.877 & 532.728 \\
\hline 1700 & 60.505 & 77.951 & 318.093 & 272.239 & 535.751 \\
\hline 1750 & 60.603 & 80.978 & 319.848 & 273.575 & 538.778 \\
\hline 1800 & 60.694 & 84.011 & 321.557 & 274.884 & 541.811 \\
\hline 1850 & 60.779 & 87.048 & 323.221 & 276.168 & 544.848 \\
\hline 1900 & 60.857 & 90.089 & 324.843 & 277.428 & 547.889 \\
\hline 1950 & 60.930 & 93.133 & 326.424 & 278.664 & 550.933 \\
\hline 2000 & 60.997 & 96.181 & 327.968 & 279.877 & 553.981 \\
\hline 2050 & 61.060 & 99.233 & 329.475 & 281.068 & 557.033 \\
\hline 2100 & 61.119 & 102.287 & 330.947 & 282.239 & 560.087 \\
\hline 2150 & 61.174 & 105.345 & 332.386 & 283.388 & 563.145 \\
\hline 2200 & 61.225 & 108.405 & 333.793 & 284.518 & 566.205 \\
\hline 2250 & 61.273 & 111.467 & 335.169 & 285.628 & 569.267 \\
\hline 2300 & 61.318 & 114.532 & 336.516 & 286.720 & 572.332 \\
\hline 2350 & 61.361 & 117.599 & 337.835 & 287.793 & 575.399 \\
\hline 2400 & 61.401 & 120.668 & 339.128 & 288.849 & 578.468 \\
\hline 2450 & 61.438 & 123.739 & 340.394 & 289.888 & 581.539 \\
\hline 2500 & 61.474 & 126.812 & 341.636 & 290.911 & 584.612 \\
\hline 2550 & 61.507 & 129.886 & 342.853 & 291.918 & 587.686 \\
\hline 2600 & 61.539 & 132.963 & 344.048 & 292.909 & 590.763 \\
\hline 2650 & 61.569 & 136.040 & 345.221 & 293.885 & 593.840 \\
\hline 2700 & 61.597 & 139.119 & 346.372 & 294.846 & 596.919 \\
\hline 2750 & 61.624 & 142.200 & 347.502 & 295.793 & 600.000 \\
\hline 2800 & 61.650 & 145.282 & 348.613 & 296.727 & 603.082 \\
\hline 2850 & 61.674 & 148.365 & 349.704 & 297.646 & 606.165 \\
\hline 2900 & 61.697 & 151.449 & 350.777 & 298.553 & 609.249 \\
\hline 2950 & 61.719 & 154.535 & 351.832 & 299.447 & 612.335 \\
\hline 3000 & 61.740 & 157.621 & 352.869 & 300.329 & 615.421 \\
\hline 3050 & 61.760 & 160.709 & 353.890 & 301.199 & 618.509 \\
\hline 3100 & 61.779 & 163.797 & 354.895 & 302.057 & 621.597 \\
\hline 3150 & 61.798 & 166.887 & 355.883 & 302.903 & 624.687 \\
\hline 3200 & 61.815 & 169.977 & 356.857 & 303.739 & 627.777 \\
\hline 3250 & 61.832 & 173.068 & 357.815 & 304.563 & 630.868 \\
\hline 3300 & 61.848 & 176.160 & 358.759 & 305.377 & 633.960 \\
\hline 3350 & 61.864 & 179.253 & 359.689 & 306.181 & 637.053 \\
\hline 3400 & 61.879 & 182.346 & 360.606 & 306.975 & 640.146 \\
\hline 3450 & 61.894 & 185.441 & 361.509 & 307.759 & 643.241 \\
\hline 3500 & 61.908 & 188.536 & 362.400 & 308.533 & 646.336 \\
\hline 3550 & 61.921 & 191.632 & 363.278 & 309.298 & 649.432 \\
\hline 3600 & 61.935 & 194.728 & 364.145 & 310.053 & 652.528 \\
\hline 3650 & 61.947 & 197.825 & 364.999 & 310.800 & 655.625 \\
\hline 3700 & 61.960 & 200.923 & 365.842 & 311.538 & 658.723 \\
\hline 3750 & 61.972 & 204.021 & 366.674 & 312.268 & 661.821 \\
\hline 3800 & 61.984 & 207.120 & 367.495 & 312.989 & 664.920 \\
\hline 3850 & 61.996 & 210.219 & 368.305 & 313.702 & 668.019 \\
\hline 3900 & 62.008 & 213.320 & 369.105 & 314.408 & 671.120 \\
\hline 3950 & 62.019 & 216.420 & 369.895 & 315.105 & 674.220 \\
\hline
\end{tabular}




\begin{tabular}{|c|c|c|c|c|c|}
\hline$T$ & CP & H-H298 & $\mathrm{S}$ & $-(\mathrm{G}-\mathrm{H} 298) / T$ & $\mathbf{H}$ \\
\hline $\mathrm{K}$ & $\mathrm{J} /(\mathrm{mol} \mathrm{K})$ & $\mathrm{kJ} / \mathrm{mol}$ & $\mathrm{J} /(\mathrm{mol} \mathrm{K})$ & $\mathrm{J} /(\mathrm{mol} \mathrm{K})$ & $\mathrm{kJ} / \mathrm{mol}$ \\
\hline 4000 & 62.031 & 219.521 & 370.675 & 315.795 & 677.321 \\
\hline 4050 & 62.042 & 222.623 & 371.446 & 316.477 & 680.423 \\
\hline 4100 & 62.053 & 225.726 & 372.207 & 317.152 & 683.526 \\
\hline 4150 & 62.064 & 228.829 & 372.959 & 317.820 & 686.629 \\
\hline 4200 & 62.076 & 231.932 & 373.703 & 318.481 & 689.732 \\
\hline 4250 & 62.087 & 235.036 & 374.437 & 319.135 & 692.836 \\
\hline 4300 & 62.098 & 238.141 & 375.164 & 319.782 & 695.941 \\
\hline 4350 & 62.109 & 241.246 & 375.882 & 320.423 & 699.046 \\
\hline 4400 & 62.120 & 244.352 & 376.591 & 321.057 & 702.152 \\
\hline 4450 & 62.131 & 247.458 & 377.293 & 321.685 & 705.258 \\
\hline 4500 & 62.143 & 250.565 & 377.988 & 322.307 & 708.365 \\
\hline 4550 & 62.154 & 253.672 & 378.674 & 322.922 & 711.472 \\
\hline 4600 & 62.166 & 256.780 & 379.354 & 323.532 & 714.580 \\
\hline 4650 & 62.178 & 259.889 & 380.026 & 324.136 & 717.689 \\
\hline 4700 & 62.190 & 262.998 & 380.691 & 324.734 & 720.798 \\
\hline 4750 & 62.202 & 266.108 & 381.349 & 325.326 & 723.908 \\
\hline 4800 & 62.214 & 269.218 & 382.001 & 325.913 & 727.018 \\
\hline 4850 & 62.227 & 272.329 & 382.645 & 326.495 & 730.129 \\
\hline 4900 & 62.240 & 275.441 & 383.284 & 327.071 & 733.241 \\
\hline 4950 & 62.253 & 278.553 & 383.916 & 327.642 & 736.353 \\
\hline 5000 & 62.266 & 281.666 & 384.541 & 328.208 & 739.466 \\
\hline 5050 & 62.280 & 284.780 & 385.161 & 328.769 & 742.580 \\
\hline 5100 & 62.293 & 287.894 & 385.775 & 329.325 & 745.694 \\
\hline 5150 & 62.308 & 291.009 & 386.382 & 329.876 & 748.809 \\
\hline 5200 & 62.322 & 294.125 & 386.985 & 330.422 & 751.925 \\
\hline 5250 & 62.337 & 297.241 & 387.581 & 330.964 & 755.041 \\
\hline 5300 & 62.352 & 300.359 & 388.172 & 331.500 & 758.159 \\
\hline 5350 & 62.367 & 303.477 & 388.757 & 332.033 & 761.277 \\
\hline 5400 & 62.383 & 306.595 & 389.338 & 332.561 & 764.395 \\
\hline 5450 & 62.398 & 309.715 & 389.913 & 333.084 & 767.515 \\
\hline 5500 & 62.415 & 312.835 & 390.483 & 333.604 & 770.635 \\
\hline 5550 & 62.431 & 315.956 & 391.048 & 334.119 & 773.756 \\
\hline 5600 & 62.448 & 319.078 & 391.608 & 334.629 & 776.878 \\
\hline 5650 & 62.466 & 322.201 & 392.163 & 335.136 & 780.001 \\
\hline 5700 & 62.483 & 325.325 & 392.713 & 335.639 & 783.125 \\
\hline 5750 & 62.501 & 328.450 & 393.259 & 336.137 & 786.250 \\
\hline 5800 & 62.519 & 331.575 & 393.800 & 336.632 & 789.375 \\
\hline 5850 & 62.538 & 334.701 & 394.337 & 337.123 & 792.501 \\
\hline 5900 & 62.557 & 337.829 & 394.869 & 337.610 & 795.629 \\
\hline 5950 & 62.576 & 340.957 & 395.397 & 338.094 & 798.757 \\
\hline 6000 & 62.596 & 344.086 & 395.921 & 338.573 & 801.886 \\
\hline
\end{tabular}




\section{References}

1 C. P. Fenimore, Proc. Combust. Inst., 13 (1971) 373-380.

2 J. A. Miller, C. T. Bowman, Prog. Energy Combust. Sci. 15 (1989) 287-338.

3 L. Cui, K. Morokuma, J. M. Bowman, S. J. Klippenstein, J. Chem. Phys. 110 (1999) 9469-9482.

4 L.V. Moskaleva, M.C. Lin, Proc. Combust. Inst. 28 (2000) 2393-2401.

5 L. B. Harding, S. J. Klippenstein, J. A. Miller, J. Phys. Chem. A, 112 (2008) 522-532. V. Vasudevan, R. K. Hanson, C. T. Bowman, D. M. Golden, and D. F. Davidson J. Phys. Chem. A, 111 (2007) 11818-11830.

A. El Bakali, L. Pillier, P. Desgroux, B. Lefort , L. Gasnot , J.F. Pauwels, I. da Costa, Fuel 85 (2006) 896909. J. A. Sutton, B. A. Williams, J. W. Fleming, Combustion and Flame 153 (2008) 465-478. A. A. Konnov, Combustion and Flame 156 (2009) 2093-2105. E. P. Clifford, P. G. Wenthold, W. C. Lineberger, G. A. Petersson, and G. B. Ellison., J. Phys. Chem. A, 101 (1997) 4338-4345.

E. P. Clifford, P. G. Wenthold, W. C. Lineberger, G. A. Petersson, K. M. Broadus, S. R. Kass, S. Kato, C. H. DePuy, V. M. Bierbaum, and G. B. Ellison, J. Phys. Chem. A, 102 (1998) 7100-7112 R. T. Bise, H. Choi, and D. M. Neumark, J. Chem. Phys. 111 (1999) 4923-4932. S. Canneaux, A. Wallet, M. Ribaucour, and F. Louis, Comput. Theor. Chem. 967 (2011) 67-74. N. Lamoureux, P. Desgroux, A. El Bakali, J. F. Pauwels, Combustion and Flame 157 (2010) 1929-1941.

B. Ruscic, R. E. Pinzon, M. L. Morton, G. von Laszewski, S. Bittner, S. G. Nijsure, K. A. Amin, M. Minkoff, and A. F. Wagner, J. Phys. Chem. A 108 (2004) 9979-9997 Wagner, J. Phys.: Conf. Ser. 16 (2005) 561-570.

E. Goos, A. Burcat and B. Ruscic, "Extended Third Millennium Ideal Gas and Condensed Phase Thermochemical Database for Combustion with updates from Active Thermochemical Tables”; available at ftp://ftp.technion.ac.il/pub/supported/aetdd/thermodynamics/ (mirrored at http://garfield.chem.elte.hu/Burcat/burcat.html), and also available from DLR webpage http://www.dlr.de/vt/en/;

last printed version: A. Burcat and B. Ruscic, “Third Millennium Ideal Gas and Condensed Phase Thermochemical Database for Combustion with updates from Active Thermochemical Tables”, ANL Report 05/20 and TAE Report 960 (2005). B. Ruscic, results obtained from Active Thermochemical Tables using the Core Thermochemical Network version 1.112, see [16]. Glarborg, Combust. Flame 159 (2012) 528-540. 
Winter, A. K. Agarwal (Eds.) 2010, Wiley and Sons, VCH.

\section{E. Goos, A. Burcat, Overview of Thermochemistry and its Application to Reaction Kinetics, in "Rate} Constant Calculation for Thermal Reactions: Methods and Applications", p. 3-32, H. DaCosta, M. Fan (Eds.), 2012, John Wiley \& Sons.

(http://media.wiley.com/product data/excerpt/08/04705823/0470582308-186.pdf)

B. J. McBride and S. Gordon, Computer Program for Calculating and Fitting Thermodynamic Functions, NASA Report 1271 (1992).

M. E. Jacox, Vibrational and Electronic Energy Levels of Polyatomic Transient Molecules, Supplement A, J. Phys. Chem. Ref. Data, 27 (1998) 115-393.

K. Hoyermann, F. Mauß, T. Zeuch, Phys. Chem. Chem. Phys. 6 (2004) 3824-3835.

S. S. Ahmed, F. Mauss, G. Moréac, T. Zeuch, Phys. Chem. Chem. Phys. 9 (2007) 1107-1126.

J. Li, Z. Zhao, A. Kazakov, M. Chaos, F. L. Dryer, J. J. Scire Jr., Int. J. Chem. Kinet. 39 (2007) 109-136.

S. S. Ahmed, F. Mauss, T. Zeuch, Z. Phys. Chem. 223 (2009) 551-563.

P. Oßwald, K. Kohse-Höinghaus, U. Struckmeier, T. Zeuch, L. Seidel, L. Leon, F. Mauss, Z. Phys. Chem. 225 (2011) 1029-1054.

I. G. Zsély, J. Zádor, T. Turányi, Int. J. Chem. Kinet. 40 (2008) 754-768.

http://www.loge.se/Products/DARS-Basic.html.

L. V. Gurvich, I. V. Veyts, and C. B. Alcock, "Thermodynamic Properties of Individual Substances", Vol. 1, Parts 1 and 2, Hemisphere, New York, 1989; id., Vol. 2, Parts 1 and 2, Hemisphere, New York, 1991.

M. W. Chase Jr., Ed. "NIST-JANAF Thermochemical Tables", $4^{\text {th }}$ ed., J. Phys. Chem. Ref. Data, Monograph 9 (1998).

H. Okabe and A. Mele, J. Chem. Phys. 51 (1969) 2100-2106.

NIST Chemistry WebBook, NIST Standard Reference Database Number 69, Eds. P.J. Linstrom and W.G. Mallard, National Institute of Standards and Technology, Gaithersburg MD, 20899, http://webbook.nist.gov, (retrieved December 2011).

J. M. L. Martin, P. R. Taylor, J. P. Francois, and R. Gijbels, Chem. Phys. Lett. 226 (1994) 475-483.

T. R. Taylor, R. T. Bise, K. R. Asmis, and D. M. Neumark, Chem. Phys. Lett. 301 (1999) 413-416.

B. Ruscic, J. V. Michael, P. C. Redfern, L. A. Curtiss, and K. Raghavachari, J. Phys. Chem. A 102 (1998) 10889-10899.

B. Ruscic, M. Litorja, and R. L. Asher, J. Phys. Chem. A 103 (1999) 8625-8633.

B. Ruscic, J. E. Boggs, A. Burcat, A. G. Csaszar, J. Demaison, R. Janoschek, J. M. L. Martin, M. L. Morton, M. J. Rossi, J. F. Stanton, P. G. Szalay, P. R. Westmoreland, F. Zabel, and T. Berces, J. Phys. Chem. Ref. Data 34 (2005) 573-588.

T. Zeuch, G. Moréac, S. S. Ahmed, F. Mauss, Combustion and Flame, 155 (2008) 651-674.

W. Hack, M. Hold, K. Hoyermann, J. Wehmeyer, T. Zeuch, Phys. Chem. Chem. Phys. 7 (2005) 19771984.

R.P. Lindstedt, G. Skevis, Combust. Sci. Technol. 125 (1-6) (1997) 73-137.

a.) http://www.grc.nasa.gov/WWW/CEAWeb/ceaHome.htm, accessed 30. July 2012.

b.) B. J. McBride, M. J. Zehe, S. Gordon, NASA Glenn coefficients for Calculating Thermodynamic 
Properties of Individual Species (2002) Glenn Research Center, Cleveland, Ohio, NASA TP - 2002-211556. V. M. Zamansky and V. V. Lissianski, Minimization of carbon loss in coal reburning, Semiannual Report No. 2 for Period February 11 - August 10, 2001, September 7, 2001, DOE Contract No. DE-FC2600NT40912, General Electric Energy and Environmental Research Corporation (GE EER). S. Garner, T. Dubois, C. Togbé, N. Chaumeix, P. Dagaut, K. Brezinsky, Combustion and Flame, 158 (2011) 2302-2313.

a.) R.S. Zhu, M.C. Lin, Int. J. Chem. Kinet. 37 (2005) 593-598.

b.) R.S. Zhu, M.C. Lin, J. Phys. Chem. A 111 (2007) 6766-6771.

c.) R.S. Zhu, H.M.T. Nguyen, M.C. Lin, J. Phys. Chem. A 113 (2008) 298-304.

A. M. Mebel, K. Morokuma, M.C. Lin, J. Chem. Phys. 103 (1995) 7414-7421.

S. Gersen, A.V. Mokhov, H.B. Levinsky, Combustion and Flame 155 (2008) 267-276.

a.) A. V. Sepman, A. V. Mokhov and H. B. Levinsky, Int. J. Hydrogen Energy 36, (2011) 4474-4481.

b.) A.V. Sepman, A.V. Mokhov and H.B. Levinsky, Int. J. Hydrogen Energy, 36 (2011) 13831-13837. D.J. Benard, C. Linnen, A. Harker, H.H. Michels, J.B. Addison, R. Ondercin, J. Phys. Chem. B 102 (1998) 6010-6019.

a.) S. Xu, M.C. Lin, J. Phys. Chem. A 111 (2007) 6730-6740.

b.) S. Xu, M.C. Lin, Proc. Combust. Inst. 32 (2009) 99-106. R.S. Zhu, S.C. Xu, M.C. Lin, Chem. Phys. Lett. 488 (2010) 121-125.

C.F. Melius, Thermochemistry and Reaction Mechanisms of Nitromethane Ignition, Journal de Physique IV Proceedings 05 (C4) C4-535 (1995), DOI : 10.1051/jp4:1995443.

a.) P. Dagaut P. Glarborg, M. U. Alzueta, The oxidation of hydrogen cyanide and related chemistry, Progress in Energy and Combustion Science 34 (2008) 1-46.

b.) NCN thermodynamical data of [55a] provided in NASA format, but not used, e.g. in S. M. Sarathy, M. J. Thomson, C. Togbé, P. Dagaut, F. Halter, C. Mounaim-Rousselle, An experimental and kinetic modeling study of n-butanol combustion, Combustion and Flame 156 (2009) 852-864. M. Hori, and N. Matsunaga, N. Marinov, W. Pitz, C. Westbrook, Proceedings of the Combustion Institute, Volume 27 (1998) 389-396. 